\title{
ЗАДЕРЖКА ОКАЗАНИЯ МЕДИЦИНСКОЙ ПОМОЩИ ПАЦИЕНТАМ С ОСТРЫМ ИНФАРКТОМ МИОКАРДА ВО ВРЕМЯ ПАНДЕМИИ COVID-19
}

\section{DELAYING MEDICAL CARE TO PATIENTS WITH ACUTE MYOCARDIAL INFARCTION DURING COVID-19 PANDEMIC}

\section{K. Prokhorov \\ N. Koriagina \\ G. Spasenkov V. Koriagin \\ A. Avdeev \\ D. Marchenko}

Summary. Relevance. The 2019 novel coronavirus infection (COVID-19) pandemic has had a major impact on patient behavior as well as on the delivery of health care. Particularly vulnerable were older people of working age who stayed at home to avoid contracting the virus, and it remains unclear how the behavior of people with acute myocardial infarction (AMI) has changed.

The aim of this study was to determine if there are delays in the provision of medical services for AMI during the COVID-19 pandemic, compared to the same period a year earlier.

Methods. In this single-center retrospective study, we evaluated the rates of patients admitted with ST-segment elevation myocardial infarction (STEMI) and non-ST-segment elevation myocardial infarction (NSTEMI) during the COVID-19 pandemic (10/01/2020-11/30/2020) compared to with patients admitted in the same period a year earlier.

Results: 147 patients were referred in 2020 and 225 in 2019 with AMI to the regional vascular center. There were 87 and 147 patients with STEMI during the pandemic and before the pandemic, respectively. The average delivery time from pain to door during the pandemic was significantly longer than in the pre-pandemic period $(612(255,1450)$ vs $341(141,705) \mathrm{min}, \mathrm{p}=0.02)$. There were $40(46 \%)$ and $33(22 \%)$ patients. who came in 12 hours after the onset of pain in the pandemic and pre-pandemic eras $(p=0.011)$. There was no significant delay in door-to-reperfusion time $(p=0.98)$. Differences were found in hospital deaths in STEMI patients. There were 40 and 78 NSTEMI patients during the pandemic and before the pandemic, respectively. In patients, the mean delivery time from pain to the door was significantly longer during the pandemic compared to the pre-pandemic period $(1880(880,4700)$ vs $604(370,934) \mathrm{min}, \mathrm{p}<0.0001)$. During the pandemic, there was a significant delay in door-to-door reperfusion time, the average time was $330(179,602)$ versus $192(90,328) \mathrm{min}(p=0.0374)$. According to the analysis results, 18 (45\%) in 2020 and 19 (24\%) in 2019 patients
Прохоров Кирилл Владимирович

Соискатель, Пермский государственный медицинский университет им. академика Е.А. Вагнера; главный врач, ГБУЗ ПК ККД kirpro059@gmail.com

Корягина Наталья Александровна Д.м.н., профессор, Пермский государственный медицинский университет им. академика Е.А. Вагнера, главный терапевт Минздрава Пермского края nina11-85@mail.ru

Спасенков Григорий Николаевич Врач-кардиолог, Соискатель, Пермский государственный медицинский университет им. академика Е.А. Вагнера spy5502@mail.ru

Корягин Владимир Сергеевич Пермский государственный медицинский университет им. академика Е.A. Вагнера vladimirkoryagin12@gmail.com Авдеев Алексей Викторович

К.м.н., дочент, Пермский государственный медицинский университет им. академика Е.А. Вагнера

svenav@mail.ru

Марченко Дарья Дмитриевна

Пермский государственный медицинский университет им. академика Е.А. Вагнера

Аннотация. Актуальность. Пандемия новой коронавирусной инфекции 2019 г. (COVID-19), оказала большое влияние на поведение пациентов, также и на процесс оказания медицинской помощи. Особенно были уязвимы люди старшего трудоспособного возраста, которые оставались дома, чтобы избежать заражения вирусом, и до сих пор остается неясным, как поведение людей с острым инфарктом миокарда (ОИМ) изменилось.

Целью данного исследования было определить, есть ли задержки в предоставлении медицинских услуг для ОИМ во время пандемии COVID-19 по сравнению с тем же период годом ранее.

Методы. В этом одноцентровом ретроспективном исследовании мы оценили показатели пациентов, поступивших с инфарктом миокарда с подъемом сегмента ST (ИMпST) и инфарктом миокарда без подъема сегмента ST (ИМбпST) в во время пандемии COVID-19 (01.10.2020-30.11.2020 г.) по сравнению с пациентами, поступившими в тот же период годом ранее.

Результаты: в 2020 году обратилось 147 пациентов и 225 в 2019 с ОИМ в региональный сосудистый центр. Было 87 и 147 пациентов с ИМпST во время пандемии и до пандемии, соответственно. В среднее время до- 
presented 12 hours after the onset of pain in the pandemic and prepandemic eras, respectively $(p=0.001)$.

Conclusions: Patients waited significantly longer during the pandemic to seek medical attention. Anti-infective protocols specific during pandemia may delay revascularization in NSTEMI patients. These results led to more than a threefold increase in the time from the onset of pain to revascularization, which increases the risk of future complications.

Keywords: COVID-19, SARS-CoV-2, Delayed revascularization, fear of COVID-19, Acute myocardial infarction. ставки от боли до двери во время пандемии было значительно больше, чем в период до пандемии $(612(255,1450)$ против $341(141,705)$ мин, p=0,02). Было 40 (46\%) и 33 (22\%) пациентов. которые обратились через 12 часов после начала боли в пандемическую и препандемическую эпо$x и(p=0,011)$. Значительной задержки времени от двери до реперфузии не было $(p=0,98)$. Выявлены различия в госпитальной смерти у пациентов с ИMпST. Было 40 и 78 пациентов с ИМбпST во время пандемии и до пандемии, соответственно. У пациентов среднее время доставки от болевого синдрома до двери было значительно больше во время пандемии по сравнению с периодом до пандемии $(1880(880,4700)$ против 604 (370, 934) мин, $p<0,0001)$. Во время пандемии наблюдалась значительная задержка времени реперфузии от двери до двери, среднее время составило $330(179,602)$ против $192(90,328)$ мин $(p=0,0374)$. По результатам анализа 18 (45\%) в 2020 году и 19 (24\%) в 2019 году пациентов обратились через 12 часов после начала боли в пандемическую и предпандемическую эпохи, соответственно $(p=0,001)$.

Выводы: пациенты значительно дольше ждали во время пандемии, чтобы обратиться за медицинской помощью. Специфические противоинфекционные протоколы во время пандемии могут отсрочить реваскуляризацию пациентов с ИMбпST. Эти результаты привели к более чем трехкратному увеличению времени от начала болевого синдрома до реваскуляризации, что увеличивает риск будущих осложнений.

Ключевые слова: COVID-19, SARS-CoV-2, Отсроченная реваскуляризация,. страх перед COVID-19, Острый инфаркт миокарда.

\section{Материалы и мето $\Delta$}

В анализ мы включили последовательных пациентов с 01 октября 2020 г. по 30 ноября 2020 г., которые обратились с ОИМ и прошли инвазивную ангиографию в региональном сосудистом центре ГБУЗ ПК Клинический кардиологический диспансер, и последовательных пациентов, госпитализированными с ОИМ с 1 октября 2019 г. по 30 ноября 2019 г.

Время от болевого синдрома до поступления определялось как время от появления симптома до момента обращения в стационар. Мы разделили время контакта на ранние и поздние группы, так, что первые пациенты сообщали о появление симптомов через 12 часов или меньше, и другие сообщили о появлении симптомов более 12 часов. От двери до реперфузии время определялось как время прибытия до проведения коронароангиографии. ИМпST и ИМбпST были определены, согласно четвертому универсальному определению инфаркта миокарда [4]. Кардиогенный шок был определен как длительная гипотензия (систолическое артериальное давление <90 мм рт. ст.). Считается, что дисфункция желудочков связана с миокардиальным повреждением или механическими осложнениями, возникшие в результате инфаркта миокарда. Успеш- 
ное чрескожное коронарное вмешательство (ЧКВ) определялось как уменьшение стеноза поражения коронарной артерии до $<30 \%$. Этот исследование было проведено в соответствии со всеми применимыми этическими принципами.

Непрерывные переменные были представлены как медиана (25-й процентиль, 75-й процентиль). Категориальные переменные представлены в виде количеств с пропорциями. Было проведено сравнение периодов (пандемия и допандемия) и стратифицированы на основании клинических проявлений (ИМбпSТ или ИМпST). Различия в пациентах характеристики и результаты между годами оценивались с помощью суммы рангов Вилкоксона и критериев хи-квадрат или критерия точного теста Фишера, в зависимости от обстоятельств. Статистический анализ проведен с использованием SPSS.

\section{Результаты}

В 2020 году обратилось 147 пациентов и 225 в 2019 с ОИМ в региональный сосудистый центр в период с 01 октября до 30 ноября.

Было 87 и 147 пациентов с ИМпST во время пандемии и до пандемии, соответственно. В среднее время доставки от боли до двери во время пандемии было значительно больше, чем в период до пандемии (612 $(255,1450)$ против $341(141,705)$ мин, $\mathrm{p}=0,02)$. Было 40 (46\%) и 33 (22\%) пациентов. которые обратились через 12 часов после начала боли в пандемическую и препандемическую эпохи, соответственно $(p=0,011)$. Значительной задержки времени от двери до реперфузии не было $(p=0,98)$. Выявлены различия в госпитальной смерти у пациентов с ИMпST.

Было 40 и 78 пациентов с ИМбпSТ во время пандемии и до пандемии, соответственно. У пациентов среднее время доставки от болевого синдрома до двери было значительно больше во время пандемии по сравнению с периодом до пандемии $(1880(880,4700)$ против 604 $(370,934)$ мин, р <0,0001). Во время пандемии наблюдалась значительная задержка времени реперфузии от двери до двери, среднее время составило 330 (179, 602) против $192(90,328)$ мин $(p=0,0374)$. По результатам анализа 18 (45\%) в 2020 году и 19 (24\%) в 2019 году пациентов обратились через 12 часов после начала боли в пандемическую и предпандемическую эпохи, соответственно $(p=0,001)$.

ЧКВ как стратегия реваскуляризации выполнялась во время пандемии чаще, чем в период до пандемии (82\% против 71\%), но при этом большее количество пациентов (18\%) перенесли экстренное шунтирование в период до пандемии по сравнению с 7,1\% во время пандемии 2020 года.

Статистические значимой разницы показателя фракция выброса левого желудочка не был (в период пандемии 45\% против 49\% в 2019 году, $\mathrm{p}=0,11$ ).

Средняя продолжительность пребывания была также различной (до пандемии $9(5,11)$ против $7(4,9)$ дней в 2020 года, $p=0,3138)$. Была зафиксирована разница в летальности (8,9\% в период пандемии vs. 4,5\% в 2019 году, $\mathrm{p}=0,04)$.

\section{Обсужление}

В исследовании мы обнаружили доказательства значительных задержек в обращении в больницу для пациентов изучается во время пандемии по сравнению с таковыми во время того же периода предыдущего года до пандемии.

Время обращения за медицинском помощью у пациентов с ИМбпST почти в 3 раза дольше во время пандемии по сравнению с перидом до пандемии, но они также испытывают значительно более длительное время ожидания реваскуляризации после госпитализации.

Пациенты с ИMпST почти вдвое дольше ждали, чтобы обратиться за медицинской помощью, но не было различий по времени реваскуляризации.

Длительность времени до обращения за медицинской помощью у пациентов с ОИМ связано с более высокими показателями смертности [5]. Фактически риск одногодичной смертности увеличивается на 7,5\% на каждые 30 минут задержки в лечении пациентов с ИМпST [6]. Размер инфаркта в значительной степени связан с продолжительностью окклюзии коронарной артерии. [7]. Хотя наблюдали значительно более длительный путь от начала болевого синдрома до двери больницы для пациентов с ОИМ во время пандемии, мы не выявили значимую разницу во фракции выброса левого желудочка у этих пациентов, но при этом имеется статистически значимая разница по уровню летальности в стационаре.

Система здравоохранения во всем мире была вынуждена внедрить протоколы, специфичные для пандемии, в попытках увеличить безопасность пациентов и медицинских работников за счет сдерживания распространения вируса [8]. Наши результаты показывают, что эти меры могут влиять на время реваскуляризации для пациентов с ИМбпST. Тот пациент, у кого есть ИМпST, все равно будет немедленно доставлен в медицинскую организацию для экстренной реваскуляризации в ожидании тестирования на COVID-19 при условии, 
что пациент не проявлял симптомов инфекции. Количество посещений отделений неотложной помощи сократилось почти на 50\% с тех пор, как была инициирована самоизоляция $[9,10]$. В нашем исследовании мы наблюдали снижение на 37\% при госпитализации ОИМ. Снижение случаев госпитализации с ОИМ могут быть связаны со страхом пациентов. заражения COVID-19 в отделении неотложной помощи и/или в кабинетах врачей. Эти наблюдения вызывают большое беспокойство со стороны с точки зрения благополучия сердечно-сосудистой системы, поскольку случаи смерти до прибытия скорой медицинской помощи становится все более актуальной для тех, кто откладывает лечение. Необходимо приложить все усилия для повышения ос- ведомленности о последствия отсрочки лечения, возможно, с использованием телемедицины и информационно-пропагандистские программ.

\section{Выво $\triangle \mathrm{b}$}

Пациенты откладывают в три раза больше необходимые медицинские и интервенционные вмешательства при ОИМ, и что протоколы, специфичные для пандемии, могут еще больше отсрочить реваскуляризацию пациентов с ИМбпST. Следует приложить все усилия для повышения осведомленности пациентов, а также скорректировать стратегии оценки состояния в стационаре, чтобы минимизировать общее время ишемии.

\section{ЛИТЕРАТУРА}

1. Zhu N., Zhang D., Wang W. et al. A novel coronavirus from patients with pneumonia in China, 2019. N Engl J Med. 2020; 382: $727-733$.

2. Katherine A. Muldoon, Kathryn M. Denize, Robert Talarico, Deshayne B. Fell, Agnes Sobiesiak, Melissa Heimerl, Kari Sampsel. (2021) COVID-19 pandemic and violence: rising risks and decreasing urgent care-seeking for sexual assault and domestic violence survivors. BMC Medicine 19:1.

3. Jesse M. Pines, Mark S. Zocchi, Bernard S. Black, Pablo Celedon, Jestin N. Carlson, Ali Moghtaderi, Arvind Venkat. (2021) The effect of the COVID-19 pandemic on emergency department visits for serious cardiovascular conditions. The American Journal of Emergency Medicine 47, 42-51.

4. Kristian Thygesen, Joseph S Alpert, Allan S Jaffe, Bernard R Chaitman, Jeroen J Bax, David A Morrow, Harvey D White, ESC Scientific Document Group; Fourth universal definition of myocardial infarction (2018), European Heart Journal https://doi.org/10.1093/eurheartj/ehy462.

5. Острый инфаркт миокарда с подъемом сегмента ST электрокардиограммы. Клинические рекомендации 2020. Российское кардиологическое общество, Ассоциация сердечно-сосудистых хирургов России. Российский кардиологический журнал. 2020;25(11):4103. doi:10.15829/1560-4071-20204103.

6. Сагайдак 0.В., Ощепкова Е.В., Попова Ю.В., и др. Подходы к оптимизации временных показателей оказания медицинской помощи больным с острым коронарным синдромом в системе Федерального регистра острого коронарного синдрома и мониторинга Минздрава России. Кардиологический вестник. 2017;4:82-7.

7. Mackay M, Ratner $P$, Nguyen $M$, et al. Inconsistent measurement of acute coronary syndrome patients' pre-hospital delay in research: a review of the literature. Eur J Cardiovasc Nurs. 2014;13(6):483-93. doi:10.1177/1474515114524866.

8. Solomon MD, McNulty EJ, Rana JS et al. The COVID-19 pandemic and the incidence of acute myocardial infarction. N Engl J Med. 2020; 383: 691-693.

9. Zhou F., Yu T., Du R. et al. Clinical course and risk factors for mortality of adult inpatients with COVID-19 in Wuhan, China: a retrospective cohort study. Lancet. 2020; 395: 1054-1062.

10. Clerkin K.J., Fried J.A., Raikhelkar J., et al. COVID-19 and cardiovascular disease. Circulation. 2020; 141: 1648-1655.

( Прохоров Кирилл Владимирович ( kirpro059@gmail.com ), Корягина Наталья Александровна ( nina1 1-85@mail.ru ),

Спасенков Григорий Николаевич ( spy5502@mail.ru ), Корягин Владимир Сергеевич ( vladimirkoryagin12@gmail.com ),

Авдеев Алексей Викторович ( svenav@mail.ru )Марченко Дарья Дмитриевна.

Журнал «Современная наука: актуальные проблемы теории и практики» 